\title{
Patient's Perception of Autonomy Support and Shared Decision Making in Physical Therapy
}

\author{
Ignaas Devisch1, Katreine Dierckx², Dominique Vandevelde², Patricia De Vriendt ${ }^{3,4}$, \\ Myriam Deveugele ${ }^{1}$ \\ ${ }^{1}$ Department of Primary Care and Family Medicine, Ghent University, Ghent, Belgium \\ ${ }^{2}$ Department of Physical Therapy, Ghent University, Ghent, Belgium \\ ${ }^{3}$ Free University Brussels, Brussels, Belgium \\ ${ }^{4}$ Artevelde University College, Ghent, Belgium \\ Email: ignaas.devisch@ugent.be
}

Received 30 April 2015; accepted 26 September 2015; published 29 September 2015

Copyright (C) 2015 by authors and Scientific Research Publishing Inc.

This work is licensed under the Creative Commons Attribution International License (CC BY). http://creativecommons.org/licenses/by/4.0/

c) (7) Open Access

\section{Abstract}

Background: Shared Decision Making (SDM) is primarily intended to enhance patient autonomy. To date, the relationship between patients' perceived levels of involvement and autonomy support has never been investigated in the field of physical therapy. Based on the recently reported extremely low level of observed SDM in physical therapy, similarly poor patient perceptions are expected. Objective: The main objectives of this study were to examine patients' perceptions of SDM and autonomy support in physical therapy and to explore the relationship between both. Design: Patient survey after real consultations in physical therapy. Methods: Patients completed the Dyadic Observing Patient Involvement (Dyadic OPTION) instrument and the Health Care Climate Questionnaire (HCCQ) to examine patients' perceived levels of SDM and autonomy support, respectively. Multilevel analyses were applied to determine the relationship between both perceptions. Results: Two hundred and twenty-nine patients, who were recruited by 13 physical therapists, agreed to participate. The median Dyadic OPTION score was 72.9 out of a total possible score of 100. The median HCCQ score was 94.3 out of a total possible score of 100. Patients' experienced level of SDM $(b=0.14 ; p<0.001)$ and patients' age $(b=0.12 ; p=0.001)$ contributed to patients' perceived autonomy support. None of the physical therapist characteristics were related to patients' perceived autonomy support. Limitations: Only 13 out of 125 therapists who were personally contacted agreed to participate. Conclusion: Using patients' perceptions, we found that a relationship between SDM and autonomy support existed. In contrast to observational studies, our study also demonstrated that the participating physical therapists individually tailored patient support by adapting their implementation of SDM to each patient. 


\section{Keywords}

\section{Shared Decision Making, Autonomy, Physical Therapy, Patient Autonomy}

\section{Introduction}

Due to growing evidence supporting that active treatment offers greater benefits to patients than passive treatment, exercise therapy in physical therapy has drawn more attention [1]. To successfully complete exercise therapy, patients must actively contribute in consultation and follow-up, as well as in the home exercise program [2]-[5]. Patient compliance to a prescribed therapy has been studied largely in smoking cessation [6], weight loss (maintenance) [7], diabetes care [8] and physical activity in patients with rheumatoid arthritis [9]. These studies have demonstrated that patient compliance is strongly related to the degree of therapist support of patients' autonomy in treatment. Consequently, patient autonomy has become an important principle in physical therapy.

Since the late 1960s, patient autonomy has gained increased attention in healthcare. It contains, at a minimum, "self-rule that is both free from controlling interference by others and from certain limitations such as inadequate understanding that prevents meaningful choice”. Consequently, therapist support of patients' autonomy requires health care providers to allow and encourage fully competent patients to make decisions about their lives and medical treatment without attempting to control those decisions. This way, an autonomous patient acts freely, in accordance with a self-chosen plan [10]. Patient autonomy is both instrumentally and intrinsically valuable. The instrumental value refers to the relationship between patients' perceived level of autonomy support provided by their therapists and various clinical benefits, such as increased or improved patient satisfaction [8], patient compliance [6]-[9] and health outcomes [8]. This way, patient autonomy may serve as an instrument to achieve clinical outcomes. The intrinsic value of autonomy indicates that the rational nature of the patient always should be treated as an end in itself, rather than solely as a means. In this case, patients' right on selfdetermination is respected because it is simply good to be autonomous [11]. In medical research, the intrinsic value of autonomy dominates its instrumental value [12] [13].

The growing interest in patient autonomy has resulted in identifying new approaches to decision making in medical treatment. Until recently, treatment decisions were predominantly controlled by the therapist. However, according to the theoretical developments in decision making, patient involvement is recommended but in such a way that the medical expertise of the therapist is not ignored. This approach is called Shared Decision Making (SDM), and it presupposes that the therapist and patient are equals in the decision making-process [12] [14]-[16].

To support patient autonomy, SDM was developed as a patient-therapist communication tool to increase patient involvement in decision making [12] [13]. The therapist must inform the patient of all possible treatment options and their respective (dis)advantages. Additionally, patients' needs and preferences must be considered before reaching a final decision that is supported by both parties [12] [14] [17].

Compared to the medical research field, studies on the concept of patient involvement are still scarce in physical therapy literature. The opportunities to use SDM in healthcare have been previously described in ethicsbased studies [18]-[22], and the current level of SDM use in physical therapy was recently investigated in an observational study performed in thirteen autonomous physical therapy settings at the Flemish part of Belgium [23]. However, our observational study [22], as well as various studies in the field of general practice [23]-[26], reported that SDM was rarely implemented in clinical practice.

The relationship between patients' perceived levels of involvement and autonomy support has not yet been investigated in physical therapy. Based on recently reported extremely low level of SDM in physical therapy, similarly poor patient perceptions of their own decisional involvement as well as their autonomy support may be expected. On the other hand, patients' subjective perceptions do not always agree with objective measures of SDM [24] [25]. In addition to in dependent assessments of patients' perceptions of SDM and autonomy support, it would be interesting to know whether patients perceive autonomy support to the same degree as patient involvement in decision making. Although in conceptual studies SDM and autonomy support are often bracketed together, it is unclear whether these concepts are perceived as an inextricably bounded pair by the patients as well. Making pronunciations upon the relationship between the level of patient involvement and autonomy support before we know patients' perception would ignore the patient as the most important person during decision 
making. Ultimately, SDM is firstly focused on the patient and his or her place during the decision-making process. Consequently, the relationship between patients' perceived levels of SDM and autonomy support warrants further investigation.

Therefore, the main objectives of this study were to examine patients' perceptions of their own decisional involvement and autonomy support in physical therapy and to explore the relationship between the perceived levels of SDM and autonomy support.

\section{Method}

Patients' perceptions of SDM and autonomy support were measured within a larger study that also assessed observed levels of SDM via audio recordings and therapist self-report data. This paper focuses on patients' perceptions.

\subsection{Patients}

From March 2010 until March 2011 two hundred and sixty-eight patients of 13 self-employed physical therapists were invited to participate in this study. Patients were recruited in the waiting room before a therapy session. Each patient was informed of the study procedures by the researcher and voluntarily gave written consent. Patients were native Dutch speakers and at least 18 years of age.

Using information provided by therapists, patients with a history of psychiatric disease or central nervous system disorder were excluded. The following information was recorded: age, gender, education level, employment status, participation in sports, prior history of physical therapy and consultation type (first consultation, neither first nor last session, last session).

The following therapist-related information was recorded: age, gender, additional training, years of work experience, working as a soloist or in a group, and status as a member of an interdisciplinary team.

\subsection{Protocol}

Immediately after the physical therapy consultation, patients completed 2 questionnaires while sitting in the waiting room: the Dyadic Observing Patient Involvement (Dyadic OPTION) instrument to measure perceived level of SDM, and the Health Care Climate Questionnaire (HCCQ) to measure perceived level of autonomy support.

\subsubsection{Dyadic OPTION Instrument}

The Dyadic OPTION instrument was developed to measure the perceived level of SDM and is derived from the OPTION instrument originally developed by Elwyn [26]. Because an external observer only assess the visible and audible elements of communication, the OPTION instrument can not tackle the non-verbal exchanges between the patient and therapist. The Dyadic OPTION instrument however measures the interpersonal and interdependent process of communication too, by asking the patient himself (Melbourne, 2011: referentie 24). Similar to the OPTION instrument, the Dyadic OPTION instrument contains 12 items (Table 1), which represent the process of SDM based on Charles' conceptualization of SDM [12] [16]. Each item of the Dyadic OPTION instrument is rated from " 0 " (no attempt to apply the behavior considered by this item) to " 4 " (the behavior of this item is exhibited to a high standard). The maximum possible score of the Dyadic OPTION instrument is 48. The Dutch version of the Dyadic OPTION instrument was based on the Dutch version of the OPTION instrument, with the exception of the direct object being changed (i.e., "the therapist explored patient's expectations..." was changed to "the therapist explored my expectations..."). The translation of the English OPTION instrument into the Dutch was performed by a forward-backward translation of two independent researchers associated with Elwyn's research team [27]. The Dutch version is available at the OPTION instrument website [28]. The Dyadic OPTION instrument has a good inter-rater reliability $(r=0.42, \mathrm{p}<0.01)$ [24], but has not yet been further validated neither in English nor in Dutch.

\subsubsection{Health Care Climate Questionnaire}

The HCCQ measures the perceived level of autonomy support and was developed based on the Self-Determination Theory proposed by Deci and Ryan [29]. The HCCQ was used for the first time in 1996 in studies of weight 
Table 1. Items of the Dyadic Observing Patient Involvement (OPTION) instrument and their corresponding scores.

\begin{tabular}{|c|c|c|c|c|c|c|c|}
\hline Item & Behavior & $\begin{array}{l}\text { Median score } \\
\text { (min - max) }\end{array}$ & $\mathbf{0}$ & 1 & 2 & 3 & 4 \\
\hline 1 & $\begin{array}{l}\text { The therapist drew attention to an identified problem as one that } \\
\text { requires a decision making process. }\end{array}$ & $3.0(0-4)$ & 7.0 & 0.0 & 8.7 & 35.4 & 48.9 \\
\hline 2 & $\begin{array}{l}\text { The therapist stated that there is more than one way to deal with the } \\
\text { identified problem. }\end{array}$ & $3.0(0-4)$ & 9.6 & 10.9 & 24.0 & 30.1 & 25.3 \\
\hline 3 & $\begin{array}{l}\text { The therapist assessed my preferred approach to receive information } \\
\text { to assist decision making. }\end{array}$ & $2.0(0-4)$ & 11.4 & 19.7 & 33.2 & 22.3 & 13.5 \\
\hline 4 & The therapist listed "options", which can include the choice of "no action." & $3.0(0-4)$ & 9.6 & 14.4 & 24.0 & 27.1 & 24.9 \\
\hline 5 & $\begin{array}{l}\text { The therapist explained the pros and cons of options to me } \\
\text { (taking "no action" is an option). }\end{array}$ & $3.0(0-4)$ & 8.3 & 5.2 & 20.5 & 37.1 & 28.8 \\
\hline 6 & $\begin{array}{l}\text { The therapist explored my expectations (or ideas) about how the problem(s) } \\
\text { are to be managed. }\end{array}$ & $3.0(0-4)$ & 4.4 & 2.2 & 7.0 & 43.7 & 42.8 \\
\hline 7 & $\begin{array}{l}\text { The therapist explored my concerns (fears) about how problem(s) } \\
\text { are to be managed. }\end{array}$ & $3.0(0-4)$ & 3.5 & 3.1 & 12.2 & 43.7 & 37.6 \\
\hline 8 & The therapist checked that I have understood the information & $3.0(0-4)$ & 2.2 & 1.7 & 4.8 & 41.5 & 49.8 \\
\hline 9 & $\begin{array}{l}\text { The therapist offered me explicit opportunities to ask questions } \\
\text { during the decision making process. }\end{array}$ & $4.0(0-4)$ & 0.9 & 0.4 & 4.8 & 31.0 & 62.9 \\
\hline 10 & $\begin{array}{l}\text { The therapist elicited my preferred level of involvement in } \\
\text { decision making. }\end{array}$ & $3.0(0-4)$ & 2.6 & 1.7 & 14.8 & 41.0 & 39.7 \\
\hline 11 & The therapist indicated the need for a decision making stage. & $3.0(0-4)$ & 5.2 & 7.0 & 27.1 & 32.3 & 28.4 \\
\hline 12 & The therapist indicated the need to review the decision. & $3.0(0-4)$ & 5.7 & 8.3 & 33.6 & 26.2 & 26.2 \\
\hline
\end{tabular}

Each behavior (1-12), as rated by the patient, is presented. The corresponding median, minimum (min) and maximum (max) scores are displayed. The score distribution for each item of the Dyadic OPTION instrument is presented as a percentage. 0: no attempt to indicate the behavior; 1: perfunctory or unclear attempt to indicate the behavior; 2: baseline skill level of the behavior; 3: the behavior is performed; 4: the behavior is achieved to a high standard.

loss (Williams GC, Grow VM, Freedman Z, Ryan RM, Deci EL. Motivational predictors of weight loss and weight-loss maintenance. J PersSoc Psychol. 1996: 70; 115-126) and smoking cessation (Williams GC, Deci EL. The National cancer institute guidelines for smoking cessation: do they motivate quitting? J Gen Intern Med: 1996: 11; ?-?), and is still used to measure the perceived level of autonomy support in studies of breast cancer (Shumway D, Griffith KA, Jagsi R, Gabram SG, Williams GC, Resnicow K. Psychometric properties of a brief measure of autonomy support in breast cancer patients. 2015: Jul 9; 15:51) and chronic low back pain (Murray A, Hall AM, Williams GC, McDonough SM, Ntoumanis N, Taylor IM, Jackson B, Matthews J, Hurley DA, Lonsdale C. Effect of a self-determination theory-based communication skills training program on physiotherapists' psychological support for their patients with chronic low back pain: a randomized controlled trial. Arch Phys Med Rehabil. 2015 May; 96(5): 809-16). The HCCQ contains 15 items, as shown in Table 2. Some items are focused on the way health care information is shared with the patient (i.e. items 1, 6, 7 and 9), some emphasizes the way a therapist listens to the patient (i.e. items 2, 10 and 14) and a few other items deals with the empathically attitude (i.e. items 3, 5, 11, 12 and 15). Respondents are asked to indicate answers to all of the items using a 7-point Likert-type scale ranging from " 1 " (strongly disagree) to "7" (strongly agree). The maximum possible score of the HCCQ is 105. In this study, a Dutch version of the HCCQ was used. The forward-backward translation of the English HCCQ was performed by two independent researchers affiliated with our research group. The HCCQ has an $\alpha$ reliability coefficient of 0.95 [7], but has not yet been further validated in Dutch.

The HCCQ was used as an outcome measurement in the present study.

\subsection{Data Analysis}

The Statistical Package for the Social Sciences (SPSS) version 21.0 was used for all data analyses.

To compare the total Dyadic OPTION and HCCQ scores, both scores were standardized to a scale ranging 
Table 2. Items of the Health Care Climate Questionnaire (HCCQ) and corresponding scores.

\begin{tabular}{|c|c|c|c|c|c|c|c|c|c|}
\hline Item & Behavior & $\begin{array}{l}\text { Median score } \\
\text { (min - max) }\end{array}$ & 1 & 2 & 3 & 4 & 5 & 6 & 7 \\
\hline 1 & I feel that my therapist has provided me choices and options. & $7.0(1-7)$ & 4.8 & 1.3 & 1.7 & 11.8 & 13.1 & 16.6 & 50.7 \\
\hline 2 & I feel understood by my therapist. & $7.0(1-7)$ & 0.4 & 0.0 & 0.0 & 0.9 & 2.2 & 16.2 & 80.3 \\
\hline 3 & I am able to be open with my therapist at our meetings. & $7.0(4-7)$ & 0.0 & 0.0 & 0.0 & 0.9 & 0.9 & 13.1 & 85.2 \\
\hline 4 & My therapist conveys confidence in my ability to make changes. & $7.0(1-7)$ & 0.4 & 0.0 & 0.0 & 6.6 & 4.8 & 24.5 & 63.8 \\
\hline 5 & I feel that my therapist accepts me. & $7.0(4-7)$ & 0.0 & 0.0 & 0.0 & 1.7 & 1.3 & 16.2 & 80.8 \\
\hline 6 & $\begin{array}{l}\text { My therapist has made sure I really understand my condition } \\
\text { and what I need to do. }\end{array}$ & $7.0(4-7)$ & 0.0 & 0.0 & 0.0 & 3.9 & 3.5 & 18.8 & 73.8 \\
\hline 7 & My therapist encourages me to ask questions. & $6.0(2-7)$ & 0.0 & 0.4 & 0.4 & 19.7 & 13.5 & 23.1 & 42.8 \\
\hline 8 & I feel a lot of trust in my therapist. & $7.0(1-7)$ & 0.4 & 0.0 & 0.0 & 2.2 & 0.9 & 18.8 & 77.7 \\
\hline 9 & My therapist answers my questions fully and carefully. & $7.0(2-7)$ & 0.0 & 0.4 & 0.0 & 3.5 & 0.9 & 19.7 & 75.5 \\
\hline 10 & My therapist listens to how I would like to do things. & $7.0(1-7)$ & 0.4 & 0.0 & 0.0 & 9.6 & 7.0 & 21.8 & 61.1 \\
\hline 11 & My therapist handles people's emotions very well. & $7.0(4-7)$ & 0.0 & 0.0 & 0.0 & 11.4 & 5.2 & 22.3 & 61.1 \\
\hline 12 & I feel that my therapist cares about me as a person. & $7.0(3-7)$ & 0.0 & 0.0 & 0.4 & 7.0 & 6.1 & 20.1 & 66.4 \\
\hline 13 & I don't feel very good about the way my therapist talks to me. & $7.0(1-7)$ & 2.6 & 2.2 & 0.4 & 1.7 & 0.4 & 10.9 & 81.7 \\
\hline 14 & $\begin{array}{l}\text { My therapist tries to understand how I see things before } \\
\text { suggesting a new way to do things. }\end{array}$ & $6.0(1-7)$ & 0.4 & 0.0 & 0.0 & 18.3 & 8.3 & 25.3 & 47.6 \\
\hline 15 & I feel able to share my feelings with my therapist. & $7.0(1-7)$ & 0.4 & 0.4 & 0.9 & 17.5 & 8.7 & 20.1 & 52.0 \\
\hline
\end{tabular}

Each behavior (1-15), as rated by the patient, is presented. The corresponding median, minimum (min) and maximum (max) scores are displayed. The score distribution for each item of the HCCQ is presented as a percentage. 1: strongly disagree; 2: moderately disagree; 3: disagree; 4: neutral; 5: agree; 6: moderately agree; 7: strongly agree.

from " 0 " to " 100 ". Because the answers on both questionnaires were non-parametrically distributed, the transformed scores are reported as medians. Patient descriptive statistics are reported as means.

Because data were nested per physical therapist, multilevel analyses were applied using linear mixed models. First, the physical therapist was entered as the "subject" and a series of univariate analyses were performed with the HCCQ (perceived autonomy support) entered as a dependent variable (Table 3, model A). Variables that were found to have a significant relationship with the outcome measure at a $0.20 \alpha$-level ( $\mathrm{p} \leq 0.20$; to avoid premature exclusion) were selected for the multilevel analyses. Next, a mixed linear model was developed with the HCCQ entered as the dependent variable and patients' age, sports participation and Dyadic OPTION score were entered as independent variables (Table 3, model B). The final model was then developed, which contained the variables that were significantly correlated to the HCCQ score in model B at an $\alpha$-level of 0.05 ( $\mathrm{p} \leq$ 0.05). The HCCQ score was entered into the final model as the dependent variable; the patients' age and Dyadic OPTION score were entered as independent variables (Table 3, model C). Parameter estimation was applied using Restricted Maximum Likelihood (RML).

\section{Results}

\subsection{Description of the Sample}

Two hundred sixty-eight patients were invited to participate in the present study, of which 242 (90.3\%) accepted. In seven cases, the assessment was prematurely discontinued due to recording failure during the consultation. Data from another six patients could not be analyzed because one or more HCCQ or Dyadic OPTION items were not answered. Consequently, 229 cases are reported in this paper (with an average of 17.6 cases (range 15 20 cases) per physical therapist). The patients' mean age was 46.3 years (range 19 - 89 years; SD 15.4 years) and 127 patients (55.5\%) were female. The distributions of the remaining demographic data are presented in Table 4. Table 5 contains a summary of the demographic data of each physical therapist. 
Table 3. Items of the Health Care Climate Questionnaire (HCCQ) and corresponding scores.

\begin{tabular}{|c|c|c|c|c|c|c|c|c|c|}
\hline & Model A & & & Model B & & & Model C & & \\
\hline Independent variables & $\begin{array}{l}\text { Adjusted } \\
\text { mean } \\
\text { difference }\end{array}$ & $95 \% \mathrm{CI}$ & p-value & $\begin{array}{l}\text { Adjusted } \\
\text { mean } \\
\text { difference }\end{array}$ & $95 \% \mathrm{CI}$ & $\mathrm{p}$-value & $\begin{array}{l}\text { Adjusted } \\
\text { mean } \\
\text { difference }\end{array}$ & $95 \%$ CI & p-value \\
\hline
\end{tabular}

Therapist characteristics

Sex

Male

Female

Age

Experience

$\begin{array}{lll}0.20 & -2.89 ; 3.30 & 0.89 \\ 0.30 & -0.08 ; 0.14 & 0.58 \\ 0.02 & -0.11 ; 0.15 & 0.71\end{array}$

Additional training

Yes

No

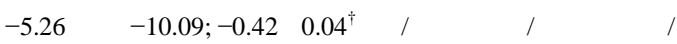

Working in group

Yes

No

$1.74 \quad-1.27 ; 4.76 \quad 0.23$

Working in interdisciplinary team

Yes

No

$0.69-3.44: 4.81 \quad 0.72$

Patient characteristics

Sex

Male

Female

Age

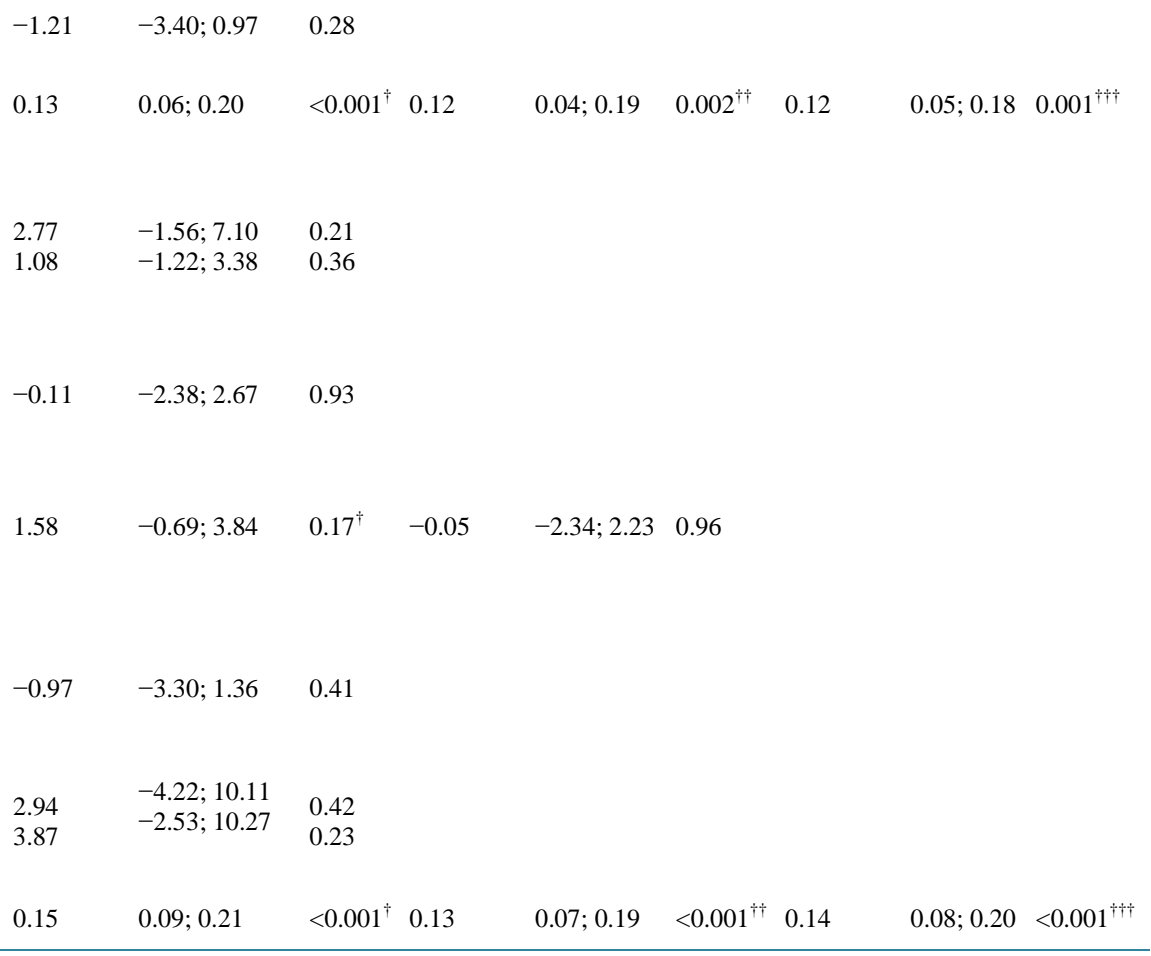

Education Level
Primary school

Secondary school

Higher education/university

Employment

Yes

No

Practicing sports

Yes

No

Prior history of consulting the

therapist for another disease

Yes

No

Consultation type

First

Neither the first nor the final

Final

frome

Model A: p-values indicate the results from the linear mixed model analysis per independent variable. ${ }^{\dagger}$ Represents significance at the $0.20 \alpha$-level. Additional training was not entered into the model because there was only a single physical therapist who did not have any additional training. Model B: p-values indicate the results from the linear mixed model analysis per independent variable. ${ }^{\dagger}$ Represents significance at the $0.05 \alpha$-level. Model C (final model): p-values indicate the results from the linear mixed model analysis per independent variable. ${ }^{\dagger+\dagger}$ Represents significance at the 0.05 $\alpha$-level. 


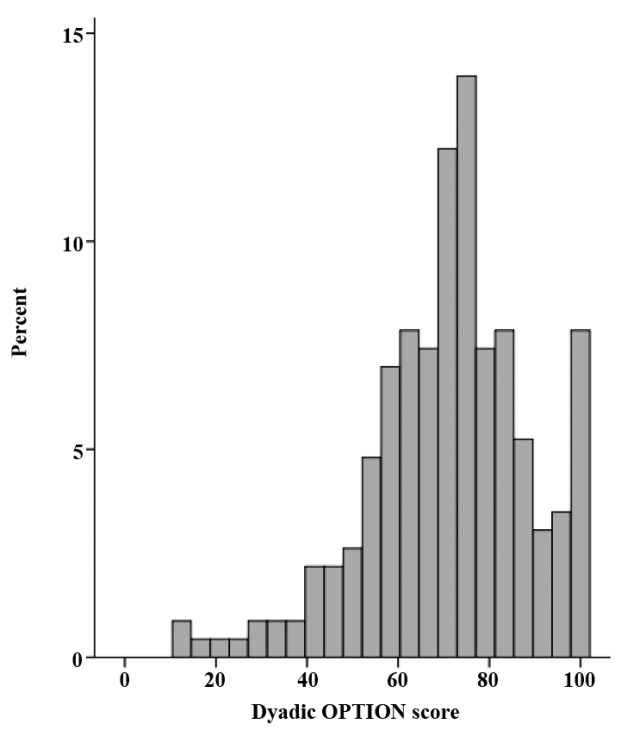

Figure 1. Distribution of the Dyadic Observing Patient Involvement (OPTION) and Health Care Climate Questionnaire (HCCQ) scores. Legend:the total possible Dyadic OPTION score was 0 - 48 and the total possible HCCQ score was 0 - 105. Both the Dyadic Option and HCCQ scores were standardized and reported on a scale ranging from 0 - 100.

Table 4. Patient demographic data.

\begin{tabular}{ll}
\hline Variables & Patients (N = 229) \\
\hline Age & $46.4(15.4)$ \\
Gender & $128(55.7 \%)$ \\
Female & $101(44.3 \%)$ \\
Male & \\
Education level & $17(7.6 \%)$ \\
Primary school & $112(48.9 \%)$ \\
Secondary school & $100(43.6 \%)$ \\
Higher education/university & \\
Employment status & $143(62.5 \%)$ \\
Employed & $86(37.5 \%)$ \\
Unemployed & \\
Practicing sports & $135(58.8 \%)$ \\
Yes & $94(41.2 \%)$ \\
No & \\
Prior history of consulting the therapist for another disease & $150(65.5 \%)$ \\
Yes & $79(34.5 \%)$ \\
No & \\
Consultation type & $24(10.6 \%)$ \\
First & $198(86.3 \%)$ \\
Feither the first nor the last & $7.1 \%)$ \\
\hline
\end{tabular}

Demographic data of all patients are displayed. Age is presented in years and as the mean followed by the standard deviation (SD); the other variables are presented as actual numbers followed by the percentages. 
Table 5. Physical therapist demographic data and the corresponding total Dyadic Observing Patient Involvement (OPTION) scores and Health Care Climate Questionnaire (HCCQ) scores.

\begin{tabular}{llllllllll}
\hline $\begin{array}{l}\text { Physical } \\
\text { therapist }\end{array}$ & Gender Age & Experience $\begin{array}{l}\text { Additional } \\
\text { training }\end{array}$ & $\begin{array}{l}\text { Working } \\
\text { in group }\end{array}$ & $\begin{array}{l}\text { Working in } \\
\text { interdisciplinary } \\
\text { team }\end{array}$ & $\begin{array}{l}\text { Number of } \\
\text { consultations }\end{array}$ & $\begin{array}{l}\text { Median dyadic } \\
\text { option score } \\
\text { (min - max) }\end{array}$ & $\begin{array}{l}\text { Median hccq score } \\
\text { (min - max) }\end{array}$ \\
\hline $\mathbf{1}$ & Female & 41 & 17 & Yes 1, 2 & Yes & No & 20 & $74.0(25-96)$ & $94.3(72-100)$ \\
$\mathbf{2}$ & Male & 55 & 21 & Yes 6 & Yes & No & 19 & $75.0(50-94)$ & $93.3(70-100)$ \\
$\mathbf{3}$ & Female & 29 & 4 & Yes 1 & No & No & 20 & $71.9(23-100)$ & $97.1(82-100)$ \\
$\mathbf{4}$ & Male & 40 & 17 & Yes 1, 4 & Yes & No & 17 & $73.0(52-90)$ & $89.5(77-100)$ \\
$\mathbf{5}$ & Female & 27 & 4 & Yes 1 & Yes & No & 17 & $70.8(35-100)$ & $89.5(75-100)$ \\
$\mathbf{6}$ & Male & 52 & 25 & Yes 1, 3, 4 & Yes & No & 19 & $75.0(46-100)$ & $95.2(67-100)$ \\
$\mathbf{7}$ & Male & 63 & 36 & Yes 5 & No & Yes & 17 & $75.0(40-100)$ & $94.3(72-100)$ \\
$\mathbf{8}$ & Female & 25 & 1 & Yes 1 & Yes & No & 15 & $77.1(50-100)$ & $94.3(73-100)$ \\
$\mathbf{9}$ & Male & 54 & 30 & Yes 1, 2, 4 & Yes & No & 18 & $72.9(33-100)$ & $90.5(76-100)$ \\
$\mathbf{1 0}$ & Male & 40 & 15 & Yes 2, 3 & No & No & 18 & $68.8(15-100)$ & $91.4(57-100)$ \\
$\mathbf{1 1}$ & Male & 55 & 28 & Yes 1 & Yes & No & 16 & $76.0(13-100)$ & $96.2(78-100)$ \\
$\mathbf{1 2}$ & Male & 61 & 30 & Yes 1 & No & No & 18 & $76.0(29-100)$ & $96.7(81-100)$ \\
$\mathbf{1 3}$ & Female 27 & 2 & No & Yes & No & 15 & $70.8(13-90)$ & $89.5(68-97)$ \\
\hline
\end{tabular}

The demographic data for each physical therapist are displayed. Age is presented in years. Experience refers to the number of years spent working as a physical therapist. Additional training refers to the subject of the training (1 manual therapy, 2 sports physical therapy, 3 movement consultant, 4 myofascial therapy, 5 cardiotraining, 6 physical education). Working in interdisciplinary team refers to the therapists' discipline (a speech therapist). For each physical therapist, the number of rated consultations is reported. The median, minimum (min) and maximum (max) Dyadic OPTION and HCCQ scores are presented; the total possible Dyadic OPTION score was 0 - 48 and the total possible HCCQ score was 0-105. Both the Dyadic Option and HCCQ scores were standardized and reported on a scale ranging from 0 - 100 .

\subsection{The Dyadic OPTION Score}

Patients' perceived involvement in decision making resulted in a non-parametric distribution of the Dyadic OPTION scores as presented in Figure 1. The median Dyadic OPTION score was 72.9 on a scale of 100 (mean 72; range 13 - 100; SD 17.8). Table 5 presents the median, minimum and maximum Dyadic OPTION score given by the patients for each physical therapist. Table 1 presents the patients' SDM ratings for each Dyadic OPTION item in the median, minimum and maximum score, as well as each item's score distribution.

\subsection{The HCCQ Score}

The distribution of patients' perceptions of autonomy support is presented in Figure 1. The median HCCQ score was 94.3 on a scale of 100 (mean 91.5; range 57 - 100; SD 8.4). The median, minimum and maximum HCCQ scores are presented for each physical therapist in Table 5. The median, minimum and maximum score for each separate item and its corresponding distribution are presented in Table 2.

The HCCQ score in relation to individual patients' characteristics and the Dyadic OPTION score.

Patients' age $(\mathrm{p}=0.001)$ and Dyadic OPTION score $(\mathrm{p}<0.001)$ were positively correlated with the HCCQ score. As the patient's age increased by one year or the Dyadic OPTION score increased by one point, the adjusted mean differences of the HCCQ was 0.12 and 0.14 , respectively (Table 3 , model C).

Although the p-value of additional training was less than 0.20 in model $\mathrm{A}$, this variable was not entered into model B or C because there was only a single physical therapist who had no additional training. The remaining variables were not significantly correlated with the HCCQ score (Table 3). Physical therapist characteristics explained $0.3 \%$ of the variance in the final model.

\section{Discussion}

This paper presents the two principle findings of our study. 
The first main finding confirms, based on the perception of the participating patients, the relationship between SDM and autonomy. The second major finding is that the participating physical therapists adapt their implementation of SDM to each individual patient, thereby custom tailoring the autonomy support of the patient.

Although SDM is strongly recommended based on the intrinsic value of patient autonomy in current healthcare [12] [13], the instrumental value of autonomy may also represent a good reason to implement SDM. As mentioned in the introduction, the relationship between SDM and autonomy in physical therapy has not been investigated to date. The ratings given by the patients participating in this study confirm the existence of this relationship: patients perceiving their autonomy to be supported also feel involved in decision making.

Considering that, in the current study, SDM is related to patients' perceptions of autonomy support and that autonomy support is related to various clinical benefits in conventional medicine such as increased or improved patient satisfaction, health outcomes and patient compliance [6]-[9], SDM may be expected to provide similar benefits.

Taking these clinical benefits and the intrinsic value of patient autonomy together, SDM is likely to be instrumentally important in physical therapy.

This appears especially true considering the increasing use of exercise therapy in treatment [1]. The success or failure of exercise therapy depends on active contributions of the patient, which renders patient compliance vitally important [2] [4] [5].

Assuming that the relationship between autonomy support and its clinical benefits applies directly to physical therapy must be approached cautiously. The evidence supporting autonomy support-related clinical benefits is based on research in conventional medicine; no research has been conducted on these factors in physical therapy to date. Consequently, whether SDM, and thus autonomy support, contributes to clinical benefits in physical therapy remains unclear. Further research is therefore urgently needed.

A second and unexpected finding is that, in the perception of the patients and based on the $0.3 \%$ explained variance, physical therapists' adapt their SDM practice to each individual patient to custom tailor their autonomy support. This result was beyond our expectations because most prior research has reported that healthcare workers develop their "own style" and apply this style to most of their patients [30]-[32]. Even in our study of physical therapy, we observed that physical therapists indeed develop their "own style" independently from their patients' characteristics. In that study, we demonstrated that female physical therapists were more likely to involve the patient in decision making than male physical therapists [23]. Based on these findings, we expected that patients' perceived levels of autonomy support would also depend on the physical therapist. However, according to the patients participating in the present study, there is no relationship between personal characteristics of the therapist and the perceived levels of autonomy support. Unfortunately, this study cannot provide an exhaustive explanation for this effect.

In addition to these major findings, we observed that patient age influenced perceived levels of autonomy support. In cases of similar levels of perceived autonomy support, the relationship between SDM and autonomy support was found to be stronger for older patients. This finding was quite remarkable because observational studies typically reveal higher levels of SDM in consultations with younger patients than in those with older patients.

A possible explanation for this relationship may be that there are discrepancies in preferred levels of involvement between these groups. Older patients may prefer to take more passive roles, whereas younger patients are more likely to be actively involved in the decision making process [33]. Similar perceived levels of SDM may possibly indicate preferences for passivity in older patients compared to younger patients. However, such preferences have not been investigated to date and must be examined in future research.

The present study demonstrated a strong relationship between the perceived levels of SDM and the perceived levels of autonomy support; however, we would like to include a critical note to this paper regarding patient scores on both the Dyadic OPTION instrument and the HCCQ.

All of the participating patients in this study indicated very high ratings on both questionnaires. This result is not consistent with the findings of our observational study, which reported very low levels of SDM in physical therapy [23]. However, the high patient scores of the current study are similar to the results of earlier published studies which investigated patients' perception. The first measurement of patients' perception with the Dyadic OPTION instrument by Melbourne et al., for instance, showed high patient scores as well. Yet, Melbourne's study was performed in simulated consultations, which hampers the comparison of both results [24]. Comparable high patient scores, a skewed distribution and a lack of score variability has also been widely demonstrated 
in studies on patients' perceived level of autonomy support [7] [24] [34]-[36]. A number of reasons may account for the high patient ratings found in the present study.

One possible explanation for high patient scores may be that patients are hesitant or not likely to be critical of their therapist [37]. Patients may feel that the Dyadic OPTION and the HCCQ ask them to evaluate their therapist. Thus, patients may not only score the particular questionnaire item but also consider their overall satisfaction with the therapist. In order to minimize patients' feeling of evaluating their therapist, the researchers emphasized the confidentiality of this study and asked to simply represent their perception on the decision-making process.

Second, despite using a meticulous explanation of SDM, it is possible that patients consider SDM as "being heard" or "feeling free to tell their story", as mentioned in a study by Saba [25]. Patients in Saba's study reported positive experiences about their involvement as well, but his results may not be strictly comparable with those of our study. Saba investigated patients' experiences of SDM in a qualitative study using semi-structured individual interviews [25]. This study investigated patients' perceived levels of SDM and autonomy support in physical therapy using quantitative measures (the Dyadic OPTION instrument and the HCCQ), investigated the relationship of both perceptions for the first time, and measured, for the first time, patients' perception of SDM in real life consultations. Thus, it is impossible to directly compare our results to those previously published elsewhere [24].

\section{Limitations of the Study}

One limitation of the present study is the small number of participating physical therapists. This reduces the generalizability of our results. It is therefore recommended to recruit a greater number of physical therapists in future research.

Additionally, as noted in the method section, the Dutch version of the Dyadic OPTION instrument was based on the Dutch version of the OPTION instrument. The translation from the original English OPTION instrument to the Dutch OPTION instrument was performed by the research group of Elwyn almost 8 years ago [27]. The forward-backward translation of the HCCQ was performed by two independent researchers contacted by our research group. Both translators were familiar with the Dutch and English languages.

The lack of reliability or validity studies on both Dutch questionnaires in physical therapy literature is a limitation as well. Although data on reliability and validity are absolutely necessary to confirm our results, the similarity between the current high patient ratings and the outcome of various patient perception studies is undeniable.

\section{Practical Implications}

Given that the current study provides more questions than answers, it is difficult to make clear recommendations. However, based on the current findings regarding patients' perceptions, there is at least one important practical guideline suggested.

Physical therapists must be strongly encouraged to implement SDM in practice because it is strongly related to the patients' feelings of being respected as an autonomous person in treatment decision making. Whether SDM implies a better perceived autonomy support or vice versa, cannot be demonstrated by this study and requires a randomized control study. In the meantime, we recommend physical therapists to listen to the preferences of their patients, encourage the patients to ask questions, provide information, offer choices, support the patients' initiatives and avoids paternalistic approaches in treatment. After all, the patient knows the most about his or her own capabilities and must be considered as the expert of his or her own life (style) [8] [38].

\section{Further Research}

Given the small number of participating therapists and the focus on autonomous physical therapy settings in the Flemish part of Belgium, this study must be considered as a pilot study. In future research, we recommend expanding the number of participating therapists and including also physical therapists working in different settings, such as hospitals or rehabilitation centers.

Given the high ratings indicated on both the Dyadic OPTION and the HCCQ, we advise investigating patients' perceptions of SDM and autonomy support using analog patients. Prior research has shown that analog patients give ratings that are similar to those given by real patients; however, the use of analog patients reduces ceiling 
effects [39]. We call also for continuing the discussion regarding the interpretation of patient surveys [24] [40] [41], considering that many patient surveys face ceiling effects [6] [7] [9] [42] [43]. As a final recommendation, a randomized control study is needed to investigate the causal relationship between the perceived level of SDM and autonomy support.

\section{Conclusion}

Using information regarding the perception of the participating patients in current physical therapy study, the relationship between SDM and autonomy support is confirmed. Our study also demonstrated that the participating therapists tailored their support of the patient by adapting their implementation of SDM to each individual patient. Finally, our results indicated that, in this study, patient age influenced the perceived levels of autonomy support.

\section{Acknowledgements}

The authors express their gratitude to the physical therapists and patients for their participation in this study.

\section{References}

[1] Moore, G.E. (2004) The Role of Exercise Prescription in Chronic Disease. British Journal of Sports Medicine, 38, 6-7. http://dx.doi.org/10.1136/bjsm.2003.010314

[2] Dean, S.G., Smith, J.A., Payne, S. and Weinman, J. (2005) Managing Time: An Interpretative Phenomenological Analysis of Patients' and Physiotherapists' Perceptions of Adherence to Therapeutic Exercise for Low Back Pain. Disability and Rehabilitation, 27, 625-636. http://dx.doi.org/10.1080/0963820500030449

[3] Hayden, J.A., van Tulder, M.W. and Tomlinson, G. (2005) Systematic Review: Strategies for Using Exercise Therapy to Improve Outcomes in Chronic Low Back Pain. Annals of Internal Medicine, 142, 776-785. http://dx.doi.org/10.7326/0003-4819-142-9-200505030-00014

[4] Rhodes, R.E. and Fiala, B. (2009) Building Motivation and Sustainability into the Prescription and Recommendations for Physical Activity and Exercise Therapy: The Evidence. Physiotherapy Theory and Practice, 25, 424-441. http://dx.doi.org/10.1080/09593980902835344

[5] Vermeire, E., Hearnshaw, H., Van, R.P. and Denekens, J. (2001) Patient Adherence to Treatment: Three Decades of Research. A Comprehensive Review. Journal of Clinical Pharmacy and Therapeutics, 26, 331-342. http://dx.doi.org/10.1046/j.1365-2710.2001.00363.x

[6] Williams, G.C. and Deci, E.L. (2001) Activating Patients for Smoking Cessation through Physician Autonomy Support. Med Care, 39, 813-823. http://dx.doi.org/10.1097/00005650-200108000-00007

[7] Williams, G.C., Grow, V.M., Freedman, Z.R., Ryan, R.M. and Deci, E.L. (1996) Motivational Predictors of Weight Loss and Weight-Loss Maintenance. Journal of Personality and Social Psychology, 70, 115-126. http://dx.doi.org/10.1037/0022-3514.70.1.115

[8] Williams, G.C., McGregor, H.A., King, D., Nelson, C.C. and Glasgow, R.E. (2005) Variation in Perceived Competence, Glycemic Control, and Patient Satisfaction: Relationship to Autonomy Support from Physicians. Patient Education and Counseling, 57, 39-45. http://dx.doi.org/10.1016/j.pec.2004.04.001

[9] Hurkmans, E.J., Maes, S., de Gucht, V., Knittle, K., Peeters, A.J., Ronday, H.K., et al. (2010) Motivation as a Determinant of Physical Activity in Patients with Rheumatoid Arthritis. Arthritis Care \& Research (Hoboken), 62, 371-377. http://dx.doi.org/10.1002/acr.20106

[10] Beauchamp, T.L. and Childress, J.F. (2001) Principles of Biomedical Ethics. 6th Edition, Oxford University Press, New York.

[11] Gauthier, C.C. (1993) Philosophical Foundations of Respect for Autonomy. Kennedy Institute of Ethics Journal, 3, 2137. http://dx.doi.org/10.1353/ken.0.0103

[12] Charles, C., Gafni, A. and Whelan, T. (1997) Shared Decision-Making in the Medical Encounter: What Does It Mean? (Or It Takes at Least Two to Tango). Social Science \& Medicine, 44, 681-692. http://dx.doi.org/10.1016/s0277-9536(96)00221-3

[13] Elwyn, G. and Miron-Shatz, T. (2010) Deliberation before Determination: The Definition and Evaluation of Good Decision Making. Health Expectations, 13, 139-147. http://dx.doi.org/10.1111/j.1369-7625.2009.00572.x

[14] Sandman, L. and Munthe, C. (2009) Shared Decision-Making and Patient Autonomy. Theoretical Medicine and Bioethics, 30, 289-310. http://dx.doi.org/10.1007/s11017-009-9114-4 
[15] Sandman, L., Granger, B.B., Ekman, I. and Munthe, C. (2011) Adherence, Shared Decision-Making and Patient Autonomy. Medicine, Health Care and Philosophy, 15, 115-127.

[16] Charles, C., Gafni, A. and Whelan, T. (1999) Decision-Making in the Physician-Patient Encounter: Revisiting the Shared Treatment Decision-Making Model. Social Science \& Medicine, 49, 651-661. http://dx.doi.org/10.1016/s0277-9536(99)00145-8

[17] Madder, H. (1997) Existential Autonomy: Why Patients Should Make Their Own Choices. Journal of Medical Ethics, 23, 221-225. http://dx.doi.org/10.1136/jme.23.4.221

[18] Swisher, L.L. (2002) A Retrospective Analysis of Ethics Knowledge in Physical Therapy (1970-2000). Physical Therapy, 82, 692-706.

[19] Ramsden, E.L. (1975) The Patient’s Right to Know. Implications for Interpersonal Communication Processes. Physical Therapy, 55, 133-138.

[20] Purtilo, R.B. (1988) Ethical Issues in Teamwork: The Context of Rehabilitation. Archives of Physical Medicine and Rehabilitation, 69, 318-322.

[21] Poulis, I. (2007) Bioethics and Physiotherapy. Journal of Medical Ethics, 33, 435-436. http://dx.doi.org/10.1136/jme.2007.021139

[22] Delany, C.M., Edwards, I., Jensen, G.M. and Skinner, E. (2010) Closing the Gap between Ethics Knowledge and Practice through Active Engagement: An Applied Model of Physical Therapy Ethics. Physical Therapy, 90, 1068-1078. http://dx.doi.org/10.2522/ptj.20090379

[23] Dierckx, K., Deveugele, M., Roosen, P. and Devisch, I. (2013) Implementation of Shared Decision Making in Physical Therapy: Observed Level of Involvement and Patient Preference. Physical Therapy, 93, 1321-1330.

[24] Melbourne, E., Roberts, S., Durand, M.A., Newcombe, R., Legare, F. and Elwyn, G. (2011) Dyadic OPTION: Measuring Perceptions of Shared Decision-Making in Practice. Patient Education and Counseling, 83, 55-57. http://dx.doi.org/10.1016/j.pec.2010.04.019

[25] Saba, G.W., Wong, S.T., Schillinger, D., Fernandez, A., Somkin, C.P., Wilson, C.C., et al. (2006) Shared Decision Making and the Experience of Partnership in Primary Care. The Annals of Family Medicine, 4, 54-62. http://dx.doi.org/10.1370/afm.393

[26] Elwyn, G., Edwards, A., Wensing, M., Hood, K., Atwell, C. and Grol, R. (2003) Shared Decision Making: Developing the OPTION Scale for Measuring Patient Involvement. Quality and Safety in Health Care, 12, 93-99. http://dx.doi.org/10.1136/qhc.12.2.93

[27] Elwyn, G., Edwards, A., Wensin, M. and Grol, R. (2005) Shared Decision Making. Measurement Using the OPTION Instrument. Cardiff University, Wales.

[28] Elwyn, G., Edwards, A., Hood, K., Robling, M., Wensing, M. and Grol, R. (2012) The OPTION-Instrument. www.optioninstrument.com

[29] Deci, E.L. and Ryan, R.M. (2013) Self-Determination Theory: An Approach to Human Motivation and Personality. University of Rochester. http://www.selfdeterminationtheory.org/

[30] De Vries, A.M., de Roten, Y., Meystre, C., Passchier, J., Despland, J.N. and Stiefel, F. (2014) Clinician Characteristics, Communication, and Patient Outcome in Oncology: A Systematic Review. Psycho-Oncology, 23, 375-381. http://dx.doi.org/10.1002/pon.3445

[31] Bertakis, K.D. (2009) The Influence of Gender on the Doctor-Patient Interaction. Patient Education and Counseling, 76, 356-360. http://dx.doi.org/10.1016/j.pec.2009.07.022

[32] Barnsley, J., Williams, A.P., Cockerill, R. and Tanner, J. (1999) Physician Characteristics and the Physician-Patient Relationship. Impact of Sex, Year of Graduation, and Specialty. Canadian Family Physician, 45, 935-942.

[33] Cullati, S., Courvoisier, D.S., Charvet-Berard, A.I. and Perneger, T.V. (2011) Desire for Autonomy in Health Care Decisions: A General Population Survey. Patient Education and Counseling, 83, 134-138.

[34] Fiscella, K., Franks, P., Srinivasan, M., Kravitz, R.L. and Epstein, R. (2007) Ratings of Physician Communication by Real and Standardized Patients. The Annals of Family Medicine, 5, 151-158. http://dx.doi.org/10.1370/afm.643

[35] Ludman, E.J., Simon, G.E., Rutter, C.M., Bauer, M.S. and Unutzer, J. (2002) A Measure for Assessing Patient Perception of Provider Support for Self-Management of Bipolar Disorder. Bipolar Disorders, 4, 249-253. http://dx.doi.org/10.1034/j.1399-5618.2002.01200.x

[36] Schmidt, K., Gensichen, J., Petersen, J.J., Szecsenyi, J., Walther, M., Williams, G., et al. (2012) Autonomy Support in Primary Care-Validation of the German Version of the Health Care Climate Questionnaire. Journal of Clinical Epidemiology, 65, 206-211. http://dx.doi.org/10.1016/j.jclinepi.2011.06.003

[37] Carr-Hill, R.A. (1992) The Measurement of Patient Satisfaction. Journal of Public Health Medicine, 14, $236-249$. 
[38] Williams, G.C. and Deci, E.L. (1996) Internalization of Biopsychosocial Values by Medical Students: A Test of SelfDetermination Theory. Journal of Personality and Social Psychology, 70, 767-779. http://dx.doi.org/10.1037/0022-3514.70.4.767

[39] van Vliet, L.M., van der Wall, E., Albada, A., Spreeuwenberg, P.M., Verheul, W. and Bensing, J.M. (2012) The Validity of Using Analogue Patients in Practitioner-Patient Communication Research: Systematic Review and Meta-Analysis. Journal of General Internal Medicine, 27, 1528-1543. http://dx.doi.org/10.1007/s11606-012-2111-8

[40] Melbourne, E., Sinclair, K., Durand, M.A., Legare, F. and Elwyn, G. (2010) Developing a Dyadic OPTION Scale to Measure Perceptions of Shared Decision Making. Patient Education and Counseling, 78, 177-183. http://dx.doi.org/10.1016/j.pec.2009.07.009

[41] Street Jr., R.L., Gordon, H. and Haidet, P. (2007) Physicians' Communication and Perceptions of Patients: Is It How They Look, How They Talk, or Is It Just the Doctor? Social Science \& Medicine, 65, 586-598. http://dx.doi.org/10.1016/j.socscimed.2007.03.036

[42] Fullwood, C., Kennedy, A., Rogers, A., Eden, M., Gardner, C., Protheroe, J., et al. (2013) Patients’ Experiences of Shared Decision Making in Primary Care Practices in the United Kingdom. Medical Decision Making, 33, 26-36.

[43] Mead, N., Bower, P. and Roland, M. (2008) The General Practice Assessment Questionnaire (GPAQ)—Development and Psychometric Characteristics. BMC Family Practice, 9, 13. http://dx.doi.org/10.1186/1471-2296-9-13 